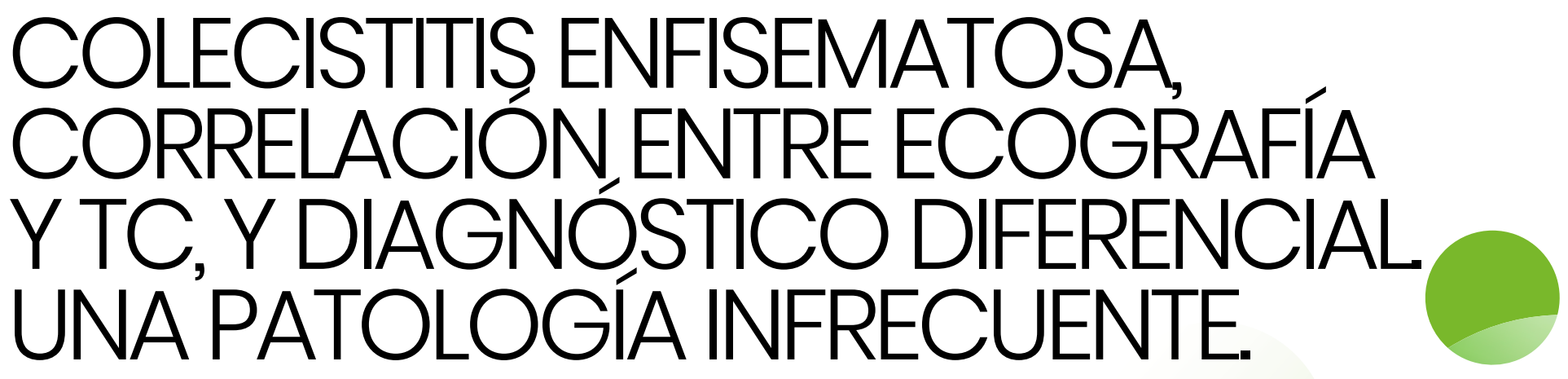

\title{
EMPHYSEMATOUS CHOLECYSTITIS, CORRELATION BETWEEN ECOGRAPHY AND CT AND DIFFERENTIAL DIAGNOSIS. A RARE PATHOLOGY.
}

\author{
Garrido Márquez I, Moyano Portillo Á, Moya Sánchez E \\ Hospital Universitario Clínico San Cecilio. Granada.
}

\section{Resumen}

La colecistitis enfisematosa es una presentación infrecuente de la colecistitis aguda, consistente en una inflamación de la vesícula biliar con presencia de gas en su pared, en su luz, o en ambas. Su diagnóstico se realiza mediante pruebas de imagen, si bien existen algunas patologías que pueden dar hallazgos similares y crear confusión, como es el caso de las fístulas bilioentéricas, que consisten en una comunicación anormal entre el sistema biliar y el tracto gastrointestinal que ocurre de forma espontánea. Las imágenes mediante tomografía computarizada suelen ser patognomónicas, siendo el tratamiento quirúrgico definitivo.

Palabras clave: colecistitis enfisematosa, fístula colecistoduodenal, ecografía, tomografía computarizada.

CORRESPONDENCIA

Irene Garrido Márquez

Hospital Universitario Clínico San Cecilio

18016 Granada

igamar26@gmail.com

Fecha de envío: 17/12/2020

Fecha de aceptación: 17/02/2021

\section{Abstract}

Emphysematous cholecystitis is an infrequent presentation of acute cholecystitis, consisting of an inflammation of the gallbladder with the presence of gas in its wall, in its lumen, or in both. Its diagnosis is made by imaging tests, although there are some pathologies that can give similar findings and create confusion, as is the case of bilioenteric fistulas, which consist of an abnormal communication between the biliary system and the gastrointestinal tract that occurs in a spontaneous. Computed tomography images are usually pathognomonic, being the definitive surgical treatment.

Keywords: emphysematous cholecystitis, cholecystoduodenal fistula, ultrasound, computed tomography.

\section{Introducción}

Presentamos un caso de un varón de 90 años con antecedentes personales de dislipemia que acude a Urgencias por dolor abdominal difuso de tres días de evolución y estreñimiento. A la exploración física sólo destacaba dolor difuso a la palpación abdominal profunda. Analíticamente se observó una leucocitosis de $19150 \times 10 \times 3 / \mu \mathrm{L}$ con PCR de $105 \mathrm{mg} / \mathrm{dl}$. Ante esta analítica, se solicitó ecografía abdominal que se complementó con TC abdominopélvica 
con contraste intravenoso yodado en fase portal. En el estudio ecográfico únicamente se visualizaba una vesícula con ecos brillantes en su pared con aumento de señal Doppler color, lo que sugería la presencia de gas intravesicular (Figura 1). La TC demostró la sospecha, apreciando una vesícula biliar de tamaño algo aumentado, con abundante contenido de barro biliar así como gran cantidad de gas tanto en la pared como en la luz, con una litiasis enclavada en su cuello y moderados cambios inflamatorios perivesiculares (Figura 2).

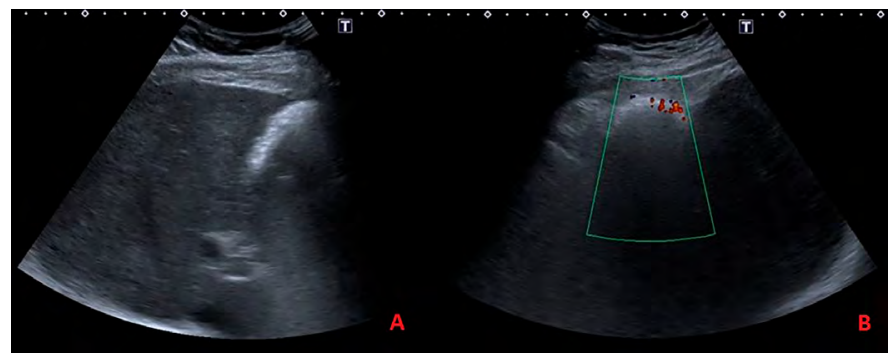

Figura 1

Imagen de ecografía abdominal en modo B (A) y Doppler color (B). Se aprecian ecos muy brillantes procedentes de la pared del cuerpo vesicular, con sombra acústica sucia y con aumento de señal Doppler color que indica aumento de vascularización, sugerente de cambios inflamatorios.

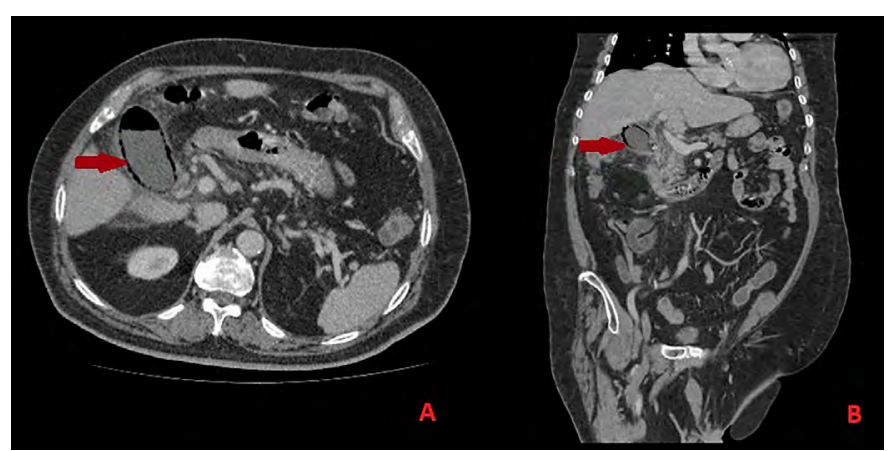

Figura 2

Imagen de TC abdominopélvica con contraste i.v. en fase portal, corte axial (A) y coronal (B). Visualizamos una vesícula biliar de tamaño aumentado, con presencia de burbujas de gas en su pared y en su interior (flechas), que asocia aumento de densidad de la grasa perivesicular en relación con cambios inflamatorios vesiculares.

El paciente comenzó con tratamiento antibiótico consistente en Piperacilina-Tazobactam $4 \mathrm{~g} / 8 \mathrm{~h}$; y fue operado de urgencia realizándose colecistectomía laparoscópica aproximadamente a las 12 horas del diagnóstico. La Anatomía Patológica confirmó los hallazgos descritos en las pruebas de imagen, que ya habían evolucionado a colecistitis gangrenosa: se obtuvo una pieza de colecistectomía de unos $8,2 \times 4,3 \mathrm{~cm}$, la cual se presentaba abierta con perforación, con serosa engrosada y adherencias fibrinosas.

En la actualidad, el paciente refiere encontrarse asintomático y con adecuada tolerancia a sólidos y líquidos.

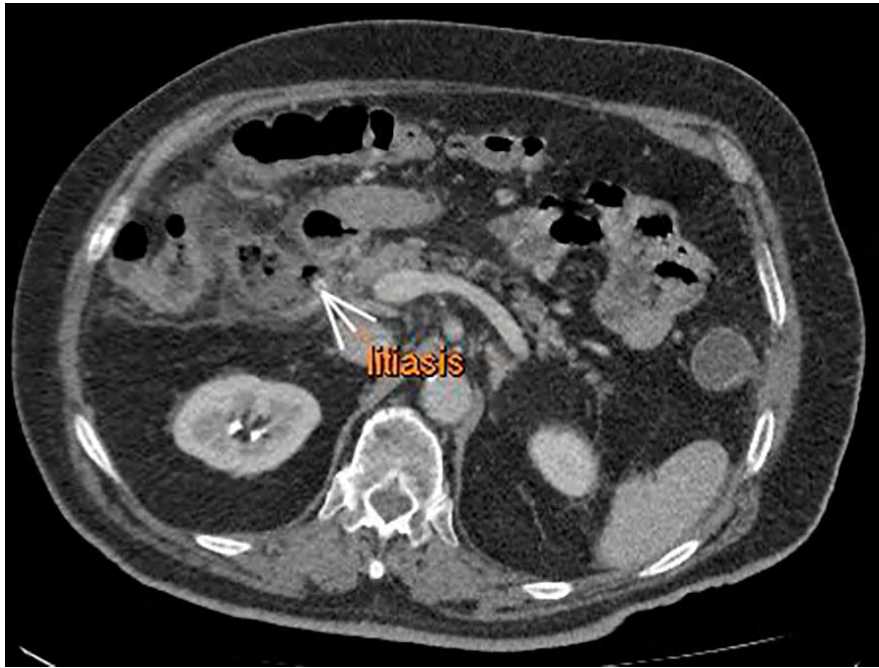

Figura 3

Imagen de TC abdominopélvica con contraste i.v. en fase portal, donde se observa una litiasis enclavada en el cuello vesicular (flecha).

\section{Discusión}

La colecistitis enfisematosa es una forma inusual de colecistitis aguda que suele aparecer en ancianos varones diabéticos. Esto se debe a que su origen está en una colecistitis aguda que evoluciona a isquemia y gangrena con formación de gas causado por diferentes microorganismos, entre los que se encuentran $\mathrm{E}$. coli, C. perfringens, Klebsiella y Streptococcus ${ }^{1}$.

La clínica y analítica es similar a la colecistitis aguda, con dolor abdominal localizado en hipocondrio derecho, Murphy positivo, leucocitosis y aumento de los parámetros de inflamación.

El diagnóstico se realiza mediante técnicas de imagen, comenzando habitualmente por ecografía abdominal pero desembocando en la mayoría de las ocasiones en TC abdominal, debido a la dificultad de visualización de la vesícula dado que el gas da una imagen ecográfica de ecos brillantes que imposibilitan la visión de las estructuras adyacentes. En la ecografía, si el gas es intraluminal podremos observar un prominente foco hiperecogénico en posición antideclive con artefacto "en cola de cometa"; por el contrario, sin el gas es intramural, suele mostrar una configuración semicircular con sombra acústica posterior, pudiendo simular una calcificación de la pared o una vesícula llena de litiasis². La TC se suele realizar con contraste intravenoso yodado en fase portal, con hallazgo típico de gas en la luz vesicular, pared o en ambas ${ }^{3}$. A menudo no se asocia a colelitiasis, si bien la perforación de la vesícula es cinco veces más frecuente en la colecistitis enfisematosa que en la colecistitis secundaria a colelitiasis ${ }^{4}$.

Sin embargo, existen otras patologías con la que es importante realizar un diagnóstico diferencial, entre las que se encuentra la fístula colecistoduodenal, una entidad muy poco frecuente $(0,15-8 \%)^{5}$. Ésta consiste en una comunicación anormal entre el sistema biliar y el tracto gastrointestinal, que suele ocurrir de forma espontánea debido al impacto de una litiasis en la bolsa de Hartmann que condiciona una erosión sobre la pared vesicular y 
órganos contiguos, con necrosis y formación del trayecto fistuloso ${ }^{5}$. En estos casos, en la TC veremos neumobilia y una vesícula atrófica adherida a órganos vecinos, pero podremos demostrar la existencia del trayecto fistuloso.

Mientras que su morbilidad es baja (1-3\%), presenta una alta mortalidad $(25 \%)^{1}$, puesto que existe un riesgo de perforación 5 veces mayor que la colecistitis aguda simple ${ }^{3}$, por lo que es necesario realizar un tratamiento precoz, que habitualmente será quirúrgico. Éste consiste en colecistectomía, normalmente laparoscópica, y si existe una fístula, a esto se añadirá una disección de las adherencias y resección del trayecto fistuloso ${ }^{5}$.

\section{Conclusión}

La colecistitis enfisematosa es una forma de presentación infrecuente de la colecistitis aguda que puede confundirse o asociarse con una fístula bilioentérica, ambas entidades con una alta mortalidad, por lo que requieren un diagnóstico rápido por imagen para establecer un tratamiento quirúrgico precoz.

\section{Bibliografía}

1. Chen M-Y, Lu C, Wang Y-F, Cai X-J. Emphysematous cholecystitis in a Young male without predisposing factors. A case report. Medicine 2016; 95:44.

2. Martín Martínez L, Duran Palacios IC, Garcés Redolat E, Eguizabal Subero C, Moratinos Yagüez C, Groba Colecistitis aguda: las múltiples caras de una gran conocida. Póster S-0954, Congreso SERAM 2014. DOI: 10.1594/ seram2014/S-0954.

3. Yen W-L, Hsu C-F, Tsai M-J. Emphysematous cholecystitis. Tzu Chi Medical Journal 2016; 28:37-38.

4. Middleton WD, Kurtz AB, Hertzberg BS. Vesícula biliar. In: Middleton WD, Kurtz AB, Hertzberg BS. Ecografía. Madrid: Marbán libros, 2007: 39-40.

5. Aguilar-Espinosa F, Maza-Sánchez R, Vargas-Solís F, Guerrero-Martínez GA, Medina-Reyes JL, Flores-Quiroz PI. Fístula colecistoduodenal, complicación infrecuente de litiasis vesicular: nuestra experiencia en su manejo quirúrgico. Revista de Gastroenterología de México 2017; 82(4): 287-295. 